Estudios Constitucionales, Año 8, No 1, 2010, pp. 249 - 282.

ISSN 0718-0195

Centro de Estudios Constitucionales de Chile Universidad de Talca

"Anomalías Constitucionales de las Superintendencias: Un diagnóstico" José Manuel Díaz de Valdés

\title{
ANOMALÍAS CONSTITUCIONALES DE LAS SUPERINTENDENCIAS: UN DIAGNÓSTICO
}

\section{Constitutional Anomalies of the Superintendencias: A Diagnosis}

\author{
José Manuel Díaz de Valdés J.2-3 \\ Profesor Universidad del Desarrollo \\ jdiazdevaldes@udd.cl
}

RESUMEN: A partir del estudio critico y sistemático de las normas emitidas por cuatro superintendencias, las disposiciones legales que les sirven de sustento habilitante y orgánico, así como la jurisprudencia y la doctrina relevantes, el artículo propone un mapa conceptual de los diversos vicios constitucionales presentes en la preceptiva jurídica de estos entes. Se afirma que tales vicios son en su mayoría comunes a las superintendencias analizadas, y que varían en su tipo y gravedad, siendo algunos de los mismos genéricos o transversales a las funciones de las superintendencias, mientras que otros se relacionan más estrechamente a alguna de sus actividades tradicionales (fiscalizadora, normativa y sancionatorialjurisdiccional).

ABSTRACT: Drawing from a critical and systematic study of the regulations issued by four superintendencias, the legal stipulations that grant their powers and determine their internal organization, as well as the relevant case-law and doctrinal work, this article proposes a conceptual map of the various constitutional flaws present on the superintendencias' legal framework. It is affirmed that those flaws, mostly common to all of the analysed superintendencias, varies in their type and seriousness, some being applicable across the spectrum of the superintendencias' legal powers, whereas some are more closely related with one of their traditional activities (inspection, regulation and sanctioning/judging).

PALABRAS CLAVE: Derecho Constitucional - Derecho Administrativo - Potestades administrativas - Superintendencias.

KEY WORDS: Constitutional Law - Administrative Law - Administrative authority - Administrative agencies.

\footnotetext{
${ }^{1}$ Artículo recibido el 31 de diciembre de 2009 y aceptado el 5 de marzo de 2010. El presente artículo forma parte de las publicaciones derivadas del proyecto "Anomalías institucionales y constitucionales de las Superintendencias", en el marco del concurso de Fondos de Investigación Universidad del Desarrollo 2008.

${ }^{2}$ Director de Investigación de la Facultad de Derecho de la Universidad del Desarrollo. Profesor de Derecho Constitucional de la Universidad del Desarrollo y de la Pontificia Universidad Católica de Chile. PRS de la Universidad de Oxford. Máster en Derecho de la Universidad de Harvard. Máster en Derecho de la Universidad de Cambridge. Magíster en Derecho Público y Licenciado en Derecho de la Pontificia Universidad Católica de Chile.

${ }^{3}$ Quisiera agradecer la acuciosa labor de investigación de las ayudantes de la Dirección de Investigación de la Universidad del Desarrollo, señoras Paulina Lobos Herrera, Camila Rodríguez Stehn, y en particular del señor Nicolás Enteiche Rosales, sin cuya persistencia y prolijidad este trabajo no hubiese sido posible. También me encuentro en deuda con los profesores Iván Aróstica Maldonado, Camila Boëttiger Philipps y José Francisco García García, por sus múltiples y acertados comentarios y sugerencias.
} 


\section{INTRODUCCIÓN}

En la actualidad, las superintendencias proyectan en Chile una imagen ambivalente. La primera dimensión es ciertamente positiva, ya que se las considera órganos serios, altamente tecnificados, dotados de recursos humanos y materiales de excepción dentro del conjunto de la Administración Pública. Sin embargo, existe también una faceta oscura, en que las superintendencias aparecen como órganos injustificadamente poderosos, dotados de un cúmulo de potestades de la más diversa índole, y capaces de infringir derechos de los regulados sin mayor control por parte de la Administración o incluso de los Tribunales de Justicia.

Para el derecho, no obstante, las superintendencias continúan siendo, en esencia, órganos administrativos descentralizados. En consecuencia, aquéllos quedan sujetos a una serie de principios constitucionalmente establecidos, tales como la separación de funciones; la juridicidad o legalidad; el control, el respeto irrestricto de los derechos fundamentales, entre otros. Sin embargo, ¿¿ocurre así en la práctica?, ¿respetan las superintendencias tales principios?, ¿ha sido el legislador suficientemente cuidadoso al diseñar y otorgar facultades a las superintendencias?

Nuestra investigación intentó dar respuesta a las preguntas anteriores desde una perspectiva estrictamente positiva, i.e., analizando las normas legales y administrativas relevantes. Dada la imposibilidad material de realizar dicho estudio en relación a todas las superintendencias existentes en el país, optamos por revisar en profundidad la situación de cuatro de ellas. Las superintendencias elegidas fueron la de Bancos e Instituciones Financieras (“SBIF”); Valores y Seguros (“SVS”); Salud (“SS”) y Casinos (“SCJ”). Las dos primeras son sin lugar a dudas las más activas e influyentes. Las dos últimas fueron elegidas por ser relativamente recientes (si bien la SS es la sucesora de la antigua Superintendencia de Isapres), lo que nos permitía observar las tendencias en el tiempo de los problemas estudiados.

Respecto a las cuatro superintendencias señaladas, se analizaron las normas emitidas por ellas que se encontraban vigentes al año 2008, así como la legislación que les sirve de fundamento y que regula la existencia y funcionamiento de tales entidades. Lo anterior se complementó con el estudio de la jurisprudencia constitucional, administrativa y judicial relevante, así como con la revisión de la doctrina especializada.

Los resultados arrojados por este estudio demuestran que, efectivamente, existen una serie de anomalías en la normativa emitida por las superintendencias, y a veces incluso en la legislación que les confiere potestades. El presente trabajo intenta presentar estos resultados en forma de diagnóstico, exponiendo de forma sistemática y dogmáticamente coherente los principales problemas y vicios que hemos detectado. Dada la gran abundancia de datos específicos sobre los cuales 
se sustentan las afirmaciones del texto, y con el ánimo de facilitar la lectura del mismo, decidimos transferir tal información (o al menos algunos ejemplos) a las notas al pie del documento.

En cuanto a la estructura del artículo, comenzaremos con algunas observaciones críticas o problemas de carácter general, para luego analizar algunas de las dificultades asociadas específicamente a las facultades fiscalizadoras, normativas, sancionatorias y jurisdiccionales de las superintendencias. Finalizaremos con las conclusiones correspondientes.

\section{Problemas o dificultades generales}

\section{Ausencia de fines claros de la regulación}

Una gran proporción de las normas legales y reglamentarias revisadas omiten la enunciación expresa de sus fines y principios inspiradores. Tal omisión nos parece altamente perjudicial, en razón de dos consideraciones principales. En primer término, sabemos que una buena regulación económica exige el cumplimiento de una serie de criterios ${ }^{4}$, tanto técnico-económicos como de carácter exclusivamente jurídicos, los cuales sirven de marco de contraste para la evaluación crítica de la normativa reguladora. Pues bien, en ambas dimensiones los fines y principios que inspiran la regulación constituyen un elemento esencial a considerar. Así, por ejemplo, para determinar si una regulación que interfiere un derecho fundamental es constitucionalmente legítima, deberá aplicarse un análisis de proporcionalidad de la norma en cuestión. Evidentemente, para tal análisis, la identificación de las finalidades que pretende obtener la regulación resulta crucial. Cuando el legislador o el administrador no han explicitado dichas finalidades, el juez se ve obligado a inferirlas, con el consiguiente riesgo de error, e incluso, de activismo judicial's.

La segunda consecuencia negativa de omitir las finalidades de la regulación consiste en la dificultad que impone al intérprete, sea éste el mismo administrador, el juez o el particular. Es así como la identificación precisa de ciertos fines y principios facilita la opción entre diversas alternativas posibles de interpretación de una misma norma, cuestión particularmente sensible en materia competencial, especialmente en el contexto de las superintendencias.

\footnotetext{
${ }^{4}$ Específicamente en relación a las superintendencias, véase (GarCía (2009), pp. 339-341; Galetovic y Sanhueza (2002), pp. 102-106 y Romero (2005), pp. 539-554). Cfr. Camacho (2005) pp. 430-432).

${ }^{5}$ No estamos afirmando, sin embargo, que el juez se encuentre obligatoriamente vinculado por las palabras del legislador, y menos del administrador. El juez conserva su libertad de apreciación, pudiendo identificar finalidades distintas a las declaradas. Tal circunstancia, no obstante, exigirá una explicación convincente del juez, cuestión que le será mucho más onerosa que cuando simplemente sigue la voluntad declarada del legislador o del administrador.
} 
En definitiva, finalidades expresas y claras permiten la delimitación de un marco jurídico y técnico más nítido para la regulación, aumentan la seguridad jurídica, permiten mayor transparencia, e incluso determinan en mayor medida las potestades públicas involucradas.

\section{Amplitud de competencias y falta o imprecisión del sustento legal}

Siguiendo la regla de oro del derecho público chileno, resulta indiscutible que toda potestad invocada por las superintendencias debe emanar de la Constitución Política (en adelante, CP) o de la ley (artículo $7^{\circ}$ de la CP). Una consecuencia evidente de este Principio de Juridicidad es que cada vez que una superintendencia emite alguna norma, aquélla debe poder vincularse a una disposición legal habilitante que confiere la respectiva potestad. En otras palabras, el contenido de toda circular, oficio circular, norma de carácter general, etc., sólo es válido en la medida que tenga un fundamento legal y competencial demostrable.

En razón de lo anterior, la Administración ha ido desarrollando una sana práctica, consistente en identificar precisamente, al comienzo de sus normas, las disposiciones legales habilitantes de competencia que dan sustento a su contenido. Dada la alta fragmentación y falta de sistematicidad del derecho administrativo chileno, tal referencia explícita resulta muy útil para quién desee controlar la legalidad de la norma.

Ahora bien, en el caso de las superintendencias, hemos notado dos vicios al respecto. En primer lugar, las competencias tienden a ser amplias, redactadas en términos muy genéricos, en ocasiones vagos, otorgando un margen tan ancho de alternativas de interpretación, que de alguna manera vacían de contenido a la garantía de la consagración legal. Esto queda de manifiesto al revisar algunas de las diversas facultades fiscalizadoras ${ }^{6}$, normativas ${ }^{7}$ y sancionatorias ${ }^{8}$ de las superintendencias estudiadas.

\footnotetext{
${ }^{6}$ E.g., artículo 12 incisos $1^{\circ}$ y $3^{\circ}$ y artículo 16 bis del Decreto con Fuerza de Ley No 3 de 1997 del Ministerio de Hacienda, Ley General de Bancos; artículo $4^{\circ}$ letra g) del Decreto Ley No 3538 de 1980; artículo 25 BIS inciso $3^{\circ}$ de la Ley No 18.933 de 1990; artículo 12 No 8 del ARTíCULO 6º de la Ley No 19.937 de 2004 y artículos 14 inciso $1^{\circ}, 21$ inciso $1^{\circ}$ y 37 No 2 de la Ley No 19.995 de 2005.

${ }^{7}$ E.g., artículos 37 inciso $2^{\circ}$ y 69 No 26 del Decreto con Fuerza de Ley No 3 de 1997 del Ministerio de Hacienda, Ley General de Bancos; artículo 22 inciso $8^{\circ}$ del Decreto con Fuerza de Ley No 707 de 1980; artículo 65 inciso $3^{\circ}$ de la Ley $N^{\circ} 18.045$ de 1981; artículo $3^{\circ}$, numeral $9^{\circ}$ y $15^{\circ}$ y artículo 38 ter inciso $2^{\circ}$ de la Ley No 18.933 de 1990; artículo 6º No 4 del ARTÍCULO 6º de la Ley No 19.937 de 2004 y artículo 18 inciso $3^{\circ}$ de la Ley No 19.995 de 2005.

${ }^{8}$ E.g., artículo 19 inciso $1^{\text {o }}$ del Decreto con Fuerza de Ley No 3 de 1997 del Ministerio de Hacienda, Ley General de Bancos; artículo 22 inciso 90 del Decreto con Fuerza de Ley № 707 de 1980; artículo 65 inciso $3^{\circ}$ de la Ley No 18.045 de 1981; el artículo 45 de la Ley No 18.933 de 1990, y artículo 46 de la Ley No 19.995 de 2005.
} 
En segundo lugar, las superintendencias suelen caer en una imprecisión manifiesta a la hora de invocar las normas legales habilitantes de sus actos. Es así como diversas circulares, oficios circulares, etc., comienzan con la críptica frase "en uso de sus facultades legales", sin mayor detalle. Al margen de cuestionar la motivación que podrían tener las superintendencias para utilizar tamaña generalidad, la consecuencia obvia es que el controlador debe realizar una ardua labor para poder determinar si todos los contenidos de la norma administrativa son efectivamente reconducibles a normas legales habilitantes. Más aún, si consideramos la amplitud con que tales normas suelen ser redactadas, nos encontramos frente a un cuadro en que el Principio de Juridicidad se haya, a lo menos, peligrosamente diluido.

Cabe destacar que los problemas antes enunciados se vinculan a uno más grave, si bien menos común. Nos referimos a aquellas situaciones donde derechamente no existe un sustento legal razonablemente sólido para la norma administrativa en cuestión. Un buen ejemplo de lo anterior lo constituye la Circular No 3.429 (2008) de la SBIF, la cual establece instrucciones para cobros de comisiones bancarias, en circunstancias que el artículo $8^{\circ}$ del DFL No 707 de 1980, Ley de Cuentas Corrientes Bancarias y Cheques otorga dicha facultad al Banco Central, y no a la SBIF. Un caso aún más dudoso es el de Circular No 025 de 3 de agosto de 1995, en virtud de la cual la SS regula e interviene en los contratos celebrados entre las ISAPRES y los particulares ${ }^{10}$.

\section{Limitación inconstitucional del control de la Contraloría General de la República}

En diversas ocasiones la legislación que regula la creación y atribuciones de las superintendencias las excluye de la fiscalización de la Contraloría General de la

\footnotetext{
${ }_{9}^{9}$ Algunos ejemplos de esta práctica pueden encontrarse en las Normas de Carácter General dictadas por la SVS, entre otras en las Normas $\mathrm{No}^{\circ}$. 30 de 10 de noviembre de 1989; 114 de 29 de marzo de 2001; 117 de 20 de abril de 2001; 118 de 15 mayo de 2001; 190 de 27 de diciembre de 2005, y 211 de 15 de enero de 2008. De la misma forma este uso aparece en las Circulares Nos. 071 de 24 de agosto de 1981; 346 de 20 de octubre de 1983; 428 de 31 de julio de 1984; 687 de 13 de febrero de 1987; 995 de 07 de febrero de 1991; 1696 de 29 de diciembre de 2003; 1697 de 30 de diciembre de 2003, y 1816 de 26 de octubre de 2006.

${ }^{10}$ La Circular No 025 de 3 de agosto de 1995 (complementada por la Circular IF No 91 de 26 de febrero de 2009), emitida por la SS, "Imparte instrucciones sobre los contratos de salud", establece el contenido "mínimo" en cuanto a, entre otras materias, el caso en que se pacte por el afiliado y la ISAPRE "la mantención del contrato por un tiempo determinado". Las consecuencias que la circular otorga a este hecho es "la renuncia del afiliado a poner término en cualquier momento al contrato", esto no se trata ni se regula en la ley. Si bien la superintendencia al emitir esta Circular se basa en el artículo $3^{\circ}$ números 2 y 9 de la Ley No 18.933 de 1990, estos son artículos únicamente otorgan competencias normativas e interpretativas genéricas a la SS.
} 
República (en adelante, "CGR”), con la sola excepción del examen de sus cuentas de entradas y gastos ${ }^{11}$.

De esta forma, el legislador limita las funciones fiscalizadoras encargadas directa y expresamente por el constituyente a la CGR en el artículo 98 de la CP. Destaca entre ellas "el control de legalidad de los actos de la Administración", de la cual las superintendencias forman parte, aun cuando de trate de entes descentralizados.

Este vicio es evidente, y así ha sido reconocido por el propio Tribunal Constitucional, quien con ocasión del control de constitucionalidad de la ley que creaba la Superintendencia de Instituciones de Salud Provisional, declaró que

"al circunscribir el texto legal en examen, la actividad del organismo contralor "exclusivamente" al análisis de las cuentas de entradas y gastos, vulnera la Constitución pues ha contemplado solamente una de las actividades y funciones que el constituyente de 1980 señaló como aquellas a ser cumplidas por Contraloría General de la República, omitiéndose entre otras la principal de ellas consistente en el ejercicio del control de la legalidad que efectuia el Contralor General a través de la "Toma de razón" de los decretos y resoluciones de los organismos y servicios que forman la administración del Estado"

Un criterio similar se observa en el control de constitucionalidad de la ley que creaba la Superintendencia de Pensiones. Nuevamente el legislador intentó restringir las facultades fiscalizadoras de la CGR, tal como lo había hecho en el caso de otras superintendencias, y el Tribunal Constitucional (en adelante, el "TC") insistió en que tal limitación sólo era constitucional si se interpretaba de forma de no excluir el control de legalidad general consagrado en el artículo 98 de la $\mathrm{CP}^{13-14}$.

El razonamiento anterior es plenamente aplicable a los otros casos en que el legislador ha intentado limitar la fiscalización de la CGR. En consecuencia, y en razón de la supremacía constitucional y del carácter del TC en cuanto intérprete final de la CP, lo correcto hoy es reinterpretar tales normas, dejando siempre

\footnotetext{
${ }^{11}$ Véase el artículo 11 del Decreto con Fuerza de Ley No 3 de 1997 del Ministerio de Hacienda, Ley General de Bancos; el artículo 25 del Decreto Ley No 3.538 de 1980, y el artículo $7^{\circ}$ inciso $3^{\circ}$ de la Ley No 18.175 de 1982.

${ }^{12}$ Tribunal Constitucional (1990) rol No 92, considerando séptimo.

${ }^{13}$ Tribunal Constitucional (2008) rol No 1032, considerando decimosexto y decimoséptimo.

${ }^{14}$ El TC consolidó su doctrina en este punto con ocasión del fallo No 1.051, de fecha 11 de julio de 2008, donde señaló que el texto legal que parecía restringir el control de la CGR sobre el Consejo para la Transparencia era constitucional en el entendido que se interpretara de forma de dejar incólume el control amplio de legalidad consagrado en el artículo 98 de la CP. Tribunal Constitucional (2008) rol No 1051, considerando trigésimo tercero y trigésimo cuarto.
} 
subsistente la fiscalización general de legalidad por parte de la CGR. De no ser asi $1^{15}$, tales preceptos quedan expuestos a recursos de inaplicabilidad por inconstitucionalidad, e incluso a una declaración de inconstitucionalidad con efectos generales (artículo $93 \mathrm{No}^{\circ}$. 6 y 7 de la $\mathrm{CP}$ ).

Cabe finalmente señalar que la CGR está recogiendo este cambio interpretativo. En efecto, durante mucho tiempo su jurisprudencia demostró una suerte de resignación a que su fiscalización se refiera sólo al examen de cuentas de entradas y gastos ${ }^{16}$. Tal actitud era entendible por cuanto la restricción en comento había tenido una creciente consagración legislativa, y la CGR no gozaba de competencia para invalidar o dejar de aplicar una ley. En otras palabras, aun cuando la CGR considerara la limitación inconstitucional, no le cabía sino obedecerla. No obstante lo anterior, los fallos del TC antes mencionados parecen estar provocando un cambio en la jurisprudencia del ente contralor ${ }^{17}$, y es así como mediante esfuerzos de "interpretación" de los preceptos legales, estaría recuperando el ejercicio de las funciones fiscalizadoras que le han sido constitucionalmente asignadas.

\section{Plazos}

En diversas ocasiones, las superintendencias imponen plazos a sus fiscalizados para realizar determinadas actuaciones, tales como contestar sus preguntas, enviar

\footnotetext{
${ }^{15}$ Aunque la realidad chilena demuestra que estos precedentes no son siempre obedecidos, véase Fermandois (2005) pp. 692-696.

${ }^{16}$ Véase, a modo de ejemplo, Contraloría General de la República (2001) Dictamen No 49090 donde se agrega la posibilidad de fiscalizar a esta superintendencia "cuando el Congreso Nacional, le solicita que requiera información en conformidad a las reglas especiales contenidas en la ley No 18.918, Ley Orgánica Constitucional del Congreso Nacional (...)”. También consúltese los dictámenes (2000) No 10555; (2001) No 7828; (2001) No 1075; (1995) No 40684; (1993) No 23443; (1990) No 31090; (1989) No 34683; (1987) No 21771, y (1985) No 15105.

Una técnica similar de limitar las competencias fiscalizadoras de la CGR consiste en señalar que el organismo público respectivo está bajo la supervigilancia exclusiva de una determinada superintendencia, o algo similar. Véase, por ejemplo, el artículo 1º del Decreto Ley No 2079 de 1978 y el artículo 33 de la Ley No 19.132 de 1992. En relación a la procedencia de las limitaciones a las facultades de la CGR sobre empresas estatales, véase Aróstica (2001) pp. 120-133.

${ }^{17}$ Contraloría General de la República (2009) No 28131, reconsiderando el criterio expresado en anteriores dictámenes, señala "en cuanto al inciso tercero del artículo 7o de la Ley № 18.175 de 1982, según el cual la Superintendencia estará sujeta a la fiscalización de la Contraloría General exclusivamente en lo concerniente al examen de las cuentas de sus entradas y gastos, corresponde señalar que tal precepto reproduce con rango legal una función de esta Entidad Contralora, constitucionalmente establecida, consistente en examinar y juzgar las cuentas de las personas que tengan a su cargo los bienes que indica, por lo que, en virtud del principio de supremacía constitucional, no ha podido afectar las demás funciones establecidas en el ya citado artículo 98 de la Carta Fundamental, entre ellas la referida al control de legalidad de sus actos". Este criterio se repite en Contraloría General de la República (2009) No 35949.
} 
documentación, informar determinados hechos, entre otros ${ }^{18}$. Sin embargo, la regla generalísima es que tales plazos no tengan una consagración legal expresa. ¿Exceden por tanto las superintendencias sus facultades legales al fijar plazos en la normativa complementaria que emiten?

En nuestra opinión, la respuesta no es absoluta sino que depende de la observancia de ciertos criterios. En primer lugar, para ser legítimo el plazo debe vincularse al cumplimiento de una obligación impuesta exclusiva y directamente por ley. Tal imposición debe ser idealmente expresa, o al menos deducirse inmediatamente de la misma (i.e., ser un requisito indispensable para el cumplimiento de la obligación legal, o una consecuencia necesaria de la misma).

En segundo lugar, debe ser un plazo razonable. Proponemos dos consideraciones para objetivar este criterio: que el plazo sea de una extensión tal que sirva para cumplir su propósito, y a la vez que permita al obligado cumplir con él sin mayores gravámenes o costos. Ambos elementos dependerán de la naturaleza de la obligación. Así, por ejemplo, la comunicación de hechos esenciales que afecten el valor de mercado de las acciones de una sociedad debe ser muy breve para que sea de utilidad. En contraste, la obligación de mandar copia del balance anual impreso que se pone a disposición de los accionistas no parece ser tan urgente. En cuanto al segundo elemento, la información acerca de la participación accionaria de una sociedad puede ser fácil y rápidamente producida por el regulado, situación

\footnotetext{
${ }^{18}$ Véase, por ejemplo, la Norma de Carácter General No 217, de 12 de junio de 2008, emitida por la SVS, la cual "Establece normas de inscripción de acciones o certificados representativos de acciones en el registro de valores extranjeros, la oferta pública de los mismos en Chile, su difusión, colocación y obligaciones de información”. Existen en ella tres casos en los que se fijan plazos máximos para la entrega de información. En los dos primeros se determina un período "dentro del tercer día hábil de ocurrido el hecho" para informar del cambio de domicilio del representante o patrocinador del emisor extranjero. El tercer caso se refiere a la obligación de entregar traducciones al idioma español de documentos presentados a la Superintendencia cuando "por su extensión requieran un plazo mayor para ser traducidos", para lo cual la Norma fija un plazo máximo de 10 días, subentendiendo que existe un plazo menor o igual para aquellas que no tengan la dificultad en su traducción. La Norma de Carácter General No 217 derogó a la Norma de Carácter General No 82, de 13 de mayo de 1999, la cual establecía plazos de "día siguiente hábil" y "dentro del plazo de los 3 días" para la entrega de determinados antecedentes e informaciones, siendo los plazos establecidos por la nueva Norma de Carácter General más laxos, lo que constituye en nuestra opinión, un avance. En la Circular No 670 de 17 de diciembre de 1986, emitida de igual forma por la SVS, la cual "regula la emisión y contenido de los certificados de derecho preferente de suscripción de acciones de pago y el registro de estos derechos. Requiere información sobre transferencia y ejercicio del derecho preferente de suscripción”, existe un caso en que la Superintendencia obliga a una sociedad, que sea requerida por un interesado, a emitir un certificado de derecho preferente de suscripción de acciones y a ponerlos a disposición de aquél "a más tardar el día hábil subsiguiente a aquel en que reciba la respectiva comunicación”. Otro ejemplo lo constituye el Oficio Circular No 7, de 6 de marzo de 2006, emitido por la SCJ, la cual responde a una solicitud de permiso de operación para casinos de juego, fijando un plazo de 10 días al solicitante para "remitir a este Servicio la información aclaratoria requerida en papel original y una copia, y además el archivo en formato excel por correo electrónico".
} 


\section{que difiere de la comunicación detallada de los datos personales actualizados de} todos sus accionistas.

Particular reproche merece la imposición por parte de las superintendencias de plazos más breves que los contemplados en la ley ${ }^{19}$, cuestión que nos parece derechamente inconstitucional. Ello por cuanto el administrador contraviene un mandato legal expreso, violando así el Principio de Juridicidad. Más aún, asume una labor legislativa que vulnera la separación de funciones contemplada en la

\footnotetext{
${ }^{19}$ Un caso de creación de un plazo es el de la Circular No 1, de 16 de abril de 2007, emitida por la SCJ, la cual "Imparte instrucciones a las sociedades operadoras sobre los plazos para desarrollar el proyecto autorizado e iniciar las operaciones del Casino de Juego conforme a los artículos 28 de la Ley No 19.995 y 37 del D.S No 211, de 2005, del Ministerio de Hacienda". Según la Ley No 19.995 de 2005, una sociedad operadora que desee operar un casino de juego debe cumplir una serie de requisitos legales, dentro de los plazos señalados por la propia ley. Desarrollado el procedimiento y una vez publicada en el Diario Oficial la resolución que otorgue el permiso de operación del Casino de Juego, la sociedad operadora deberá, de acuerdo al artículo 28 incisos $1^{\circ}$ y $2^{\circ}$ (y de similar forma en el D.S. 211, de 2005, del Ministerio de Hacienda en su artículo 37 letras a), b), c), d) y e)) "desarrollar el proyecto integral autorizado dentro del plazo establecido en el plan de operación, el cual no podrá exceder de dos años tratándose del inicio de la operación del casino propiamente tal, y de tres años para el cumplimiento de las demás obras o instalaciones que comprenda el proyecto (...) lo anterior, sin perjuicio que, antes del vencimiento de los referidos plazos, la sociedad hubiere obtenido de la Superintendencia una prórroga (...)". El inciso siguiente agrega que "vencidos los respectivos plazos o la prórroga, sin que se haya dado cumplimiento a las actividades correspondientes, el permiso se entenderá revocado (...)", finalmente el inciso $3^{\circ}$ señala "El operador que se encuentre en condiciones de iniciar la operación de un casino de juego deberá comunicarlo a la Superintendencia, la que dispondrá de 30 días para revisar el estricto cumplimiento de las obligaciones legales y reglamentarias necesarias para iniciar las actividades. Verificado dicho cumplimiento, la Superintendencia expedirá un certificado en el que conste tal circunstancia, documento que habilitará para dar inicio a la operación del Casino de Juego. Si la Superintendencia observare algunas materias, las señalará expresamente mediante resolución. En este último caso, el operador deberá subsanar tales observaciones y solicitar una nueva revisión con el objeto que la Superintendencia expida el certificado indicado y así dar poder dar inicio a la operación (...)". La imposición del plazo, no contemplado en la ley ni el reglamento, dice relación con aquella antelación en virtud de la cual, en palabras de la referida Circular, "debe efectuarse" la comunicación a la Superintendencia de estar en condiciones de iniciar las operaciones del casino de juego. El plazo exigido por este acto administrativo es de "60 días de antelación a la fecha de vencimiento de los plazos previstos en sus respectivos planes de operación o de las prórrogas que se hayan autorizado". Por lo tanto, y en términos simples, la imposición de la Superintendencia reduce en un mes (al descontarse el plazo legal de 30 días con que cuenta la Superintendencia para revisar el cumplimento de las condiciones legales y reglamentarias y emitir el certificado que constate este hecho) los plazos contemplados para desarrollar el proyecto integral autorizado. El motivo en el que se basa la SCJ para elaborar tal imposición es "permitir, por una parte, que la Superintendencia pueda verificar el estricto cumplimiento tanto de las obligaciones legales y reglamentarias necesarias para iniciar dichas actividades como de las condiciones establecidas en el respectivo permiso de operación -para lo cual dispone de 30 días- y, por otra, posibilitar que las propias sociedades operadoras subsanen las eventuales observaciones formuladas y soliciten una nueva revisión a la Superintendencia, todo lo cual ha de efectuarse dentro de los referidos plazos". Si bien podría pensarse que el plazo está establecido para proteger al particular, el resultado es inverso. Una solución factible, sería que ante el inminente cumplimiento del plazo, la Superintendencia prorrogara el plazo máximo legal (de 2 ó 3 años respectivamente). Así existiría una adecuada aplicación de la ley y el reglamento, protegiéndose el derecho de la sociedad operadora que se encuentre de buena fe.
} 
CP. Finalmente, la disminución de plazos normalmente resulta en un perjuicio para el libre ejercicio de los derechos del administrado/regulado.

\section{Problemas de actualización y sistematización}

Otra dificultad que hemos descubierto dice relación con la dificultad de identificar con certeza la normativa administrativa vigente y su vinculación a las respectivas normas legales habilitantes.

En efecto, tanto las leyes como las normas administrativas van siendo modificadas, derogadas o reemplazadas en el tiempo. Ello produce al menos dos tipos de problemas. El primero consiste en que, no obstante el gran esfuerzo que realizan las superintendencias al dictar una nueva norma, reflejando casi-inmediatamente su efecto en las disposiciones administrativas preexistentes (i.e., eliminando o reemplazando las secciones correspondientes en la normativa anterior), en diversas ocasiones ello no se logra plenamente. Como resultado, siguen apareciendo como vigentes normas que ya no lo están, o cuya vigencia es a lo menos dudosa ${ }^{20}$.

El segundo problema dice relación con la adecuada singularización de las normas legales habilitantes. Es así como algunas Circulares, Normas de Carácter General (en adelante, "NCG", etc., hacen referencia a preceptos legales que hoy no presentan conexión alguna con la materia en cuestión ${ }^{21}$, ya sea porque fueron derogados (situación más grave, ya que podría haber desaparecido el único fundamento legislativo del acto administrativo), o han cambiado de lugar dentro del cuerpo normativo en cuestión (e.g., se invoca el antiguo artículo 35 de una ley,

\footnotetext{
${ }^{20}$ Así, por ejemplo, en las Normas de Carácter General Nos. 57, de 2 de febrero de 1995; 76, de 21 de agosto de 1997 y 85, de 08 de septiembre de 1999, emitidas por la SVS, y no modificadas o derogadas, la superintendencia determina once casos de títulos de crédito susceptibles de ser adquiridos por sociedades securitizadoras. Los actos administrativos individualizados se remiten únicamente a la facultad que les otorgaría el artículo 135 inciso $1^{\circ}$ de la Ley No 18.045 de 1981. Sin embargo, el referido artículo jamás otorga tal facultad, sólo contiene remisiones a múltiples leyes que podrán determinar otros títulos de crédito. Lo que sucede es el artículo $1^{\circ}$ letra b) de la Ley No 19.301 de 1994, creo el título XVIII de la Ley No 18.045 de 1981, y consecuentemente el artículo 135 ya referido, en él se señalaba que "La Superintendencia, mediante normas de carácter general, podrá determinar otros títulos de crédito susceptibles de ser adquiridos por estas sociedades". Posteriormente, este inciso $1^{\circ}$ fue sustituido por la Ley No 19.623 de 1999, por lo que la facultad de la superintendencia fue eliminada y no aparece en el texto que las Normas de Carácter General, hoy vigentes, utilizan de sustento normativo.

${ }^{21}$ A modo de ejemplo, en la Circular Conjunta No 960 de 14 de agosto de 1990, emitida por la SVS y la SBIF, no modificada en lo pertinente, la cual se refiere a "Giro bancario. Correduría de dinero o créditos y títulos de valores”, el instrumento se remite al artículo 34 del Decreto con Fuerza de Ley No 3 de 1997 del Ministerio de Hacienda, Ley General de Bancos, señalando que éste establece "prohibiciones a las personas que no tengan una expresa autorización legal para dedicarse al giro bancario". Sin embargo, el referido artículo trata acerca de los bancos extranjeros en Chile, sin mencionar lo señalado por las superintendencias. Por el contrario, es el artículo 39 del referido texto legal el que trata la materia especificada.
} 
en circunstancias que hoy ese artículo es el 46). Si bien esta segunda hipótesis es mucho menos seria que la primera, igualmente puede dificultar la debida inteligencia y análisis de las normas administrativas.

\section{Facultades de Interpretación}

Todas las superintendencias estudiadas cuentan con facultades conferidas expresamente por el legislador ${ }^{22}$ para interpretar la normativa sectorial respectiva (incluyendo disposiciones legales y administrativas). Si bien algunos preceptos habilitantes parecían entender esta competencia como fiscalizadora ${ }^{23}$, creemos que la naturaleza de esta potestad dependerá del ejercicio que se haga de la misma. En efecto, si por interpretación entendemos el mero proceso de determinación que se produce en la aplicación de la normativa a un caso determinado, nos parece evidente que se trata de una facultad fiscalizadora. Ello aun cuando en dicho proceso la superintendencia pueda determinar ciertas oscuridades o ambigüedades de la regulación que está aplicando. Sin embargo, si por interpretación entendemos la actividad que "en ausencia de puntos oscuros que aclarar, en verdad no se restringen a declarar el sentido de las leyes, sino que razonan con miras, o a alterar un estatus jurídico anterior, dirimiendo una situación controvertida, o a innovar en el ordenamiento jurídico vigente, expresando la voluntad de mandar prohibir o permitir (...)" (Aróstica 2006, p. 149), claramente nos hallamos frente a una manifestación normativa.

En cuanto a la vinculatoriedad de las interpretaciones que realizan las superintendencias, debemos recordar que los propios textos legales habilitantes señalan que se trata de una interpretación "administrativa”. En otras palabras, no se trata de una interpretación auténtica, al menos en cuanto versa sobre leyes o reglamentos, i.e., realizada por el propio órgano que la dictó y por tanto de igual vinculatoriedad que la norma interpretada. Por tanto, se trata de una interpretación que, en estricto rigor, obliga a la propia superintendencia que la realiza y al resto de la Administración del Estado, con la posible excepción de la CGR ${ }^{24}$. Los particulares mantienen, sin embargo, la oportunidad de impugnar tal interpretación ante los

\footnotetext{
${ }^{22}$ Artículo 12 del Decreto con Fuerza de Ley No 3 de 1997 del Ministerio de Hacienda, Ley General de Bancos; artículo $4^{\circ}$ letra a) del Decreto Ley No 3538 de 1980; artículo $3^{\circ}$ No $^{2}$ de la Ley No 18.933 de 1990, y el artículo 42 No7 de la Ley No 19.995 de 2005. Véase también Aróstica (2006) pp. 151-152.

${ }^{23}$ El artículo 12 del Decreto con Fuerza de Ley No 3 de 1997 del Ministerio de Hacienda, Ley General de Bancos, señala que "La facultad de fiscalizar (SBIF) comprende también las de aplicar o interpretar las leyes, reglamentos y demás normas que rijan a las empresas vigiladas".

${ }^{24}$ Contraloría General de la República (1995) Dictamen No 41909 y Contraloría General de la República (1991) Dictamen No 30909.
} 
Tribunales de Justicia (tal y como ocurre con los dictámenes de la CGR), quienes ciertamente no podrían considerarse sujetos a aquélla sin afectar drásticamente estándares mínimos de separación de funciones ${ }^{25}$.

Estas facultades han dado lugar a dos problemas principales. En primer término, existe el peligro de que, vía interpretación, las superintendencias complementen o derechamente alteren o muten la normativa aplicable. En segundo lugar, la naturaleza "técnica" de las superintendencias impulsa a los Tribunales de Justicia a ser particularmente deferentes hacia sus interpretaciones de la normativa sectorial, lo que en la práctica las convierte en inimpugnables y de la misma jerarquía que la norma que interpretan.

\section{FACULTADES FISCALIZADORAS \\ 1. Excesivamente amplias}

Si bien la fiscalización es la razón de ser fundamental de las superintendencias, nos parece que la consagración legal de estas potestades es exageradamente amplia. Un excelente ejemplo de lo anterior lo constituye el artículo 12 del Decreto con Fuerza de Ley No 3 de 1997 del Ministerio de Hacienda, Ley General de Bancos ${ }^{26}$, cuyos primeros incisos señalan lo siguiente:

"Corresponderá al Superintendente velar porque las instituciones fiscalizadas cumplan con las leyes, reglamentos, estatutos y otras disposiciones que las rijan y ejercer la más amplia fiscalización sobre todas sus operaciones y negocios

La facultad de fiscalizar comprende también las de aplicar o interpretar las leyes, reglamentos y demás normas que rijan a las empresas vigiladas.

Para los efectos indicados, podrá examinar sin restricción alguna y por los medios que estime del caso, todos los negocios, bienes, libros, cuentas, archivos, documentos y correspondencia de dichas instituciones y requerir de sus administradores y personal, todos los antecedentes y explicaciones que juzgue necesarios para su información acerca de su situación, de sus recursos, de la forma en que se administran sus negocios, de la actuación de sus personeros, el grado de seguridad y prudencia con que se hayan invertido sus fondos y en general, de cualquier otro punto que convenga esclarecer." (el subrayado es nuestro).

Como puede fácilmente observarse, se trata de un lenguaje que da la falsa sensación de no reconocer límites, y de otorgar un haz de potestades con muy pocos elementos reglados, dejando gran espacio a la discrecionalidad administrativa. Cabe a este respecto recordar que, al margen del lenguaje que utiliza la ley, toda la potestad es un "poder jurídico-deber finalizado" (Sото KLOss 1996, p. 52), que

${ }^{25}$ Aróstica (2006), pp. 155-156; Evans Espiñeira (2006), 122-123).

${ }^{26}$ Para observar otros ejemplos, véase supra nota 6. 
debe utilizarse en forma proporcionada y siempre orientada a la finalidad que la justifica, y que su ejercicio impone exigencias en cuanto al procedimiento y a las formas (artículo $7^{\circ}$ de la CP), así como el pleno respeto de los derechos de las personas (artículo $1^{\circ}$ de la $\mathrm{CP}$ ). Nos referimos a limitaciones de carácter constitucional, por lo que ninguna ley podría relativizarlas o eliminarlas.

Es más, el propio Tribunal Constitucional se ha pronunciado sobre este punto, a propósito de una norma similar que otorgaba a la Unidad de Análisis Financiero la facultad de "Solicitar los antecedentes que estime necesarios, sean informes, documentos o de otra naturaleza a personas naturales y jurídicas, las cuales estarán obligadas a proporcionarlos en el término que se les fije”. Aquella norma fue declarada inconstitucional justamente porque se trataba de una habilitación que se otorgaba "sin trazar en la ley las pautas o parámetros, objetivos y controlables, que garanticen que el órgano administrativo pertinente se ha circunscrito a ellos, asumiendo la responsabilidad consecuente cuando los ha transgredido (...) la disposición en examen merece ser calificada como discrecional, es decir, abierta, por la indeterminación que contiene (...) circunstancia que reviste gravedad singular tratándose de la dignidad $y$ de los derechos esenciales ya comentados ${ }^{27}$ [derecho al respeto y protección de la vida privada y a la inviolabilidad del hogar las comunicaciones privadas].

En definitiva, la alternativa es clara: o interpretamos la norma transcrita en forma textual, en cuyo caso su amplitud y discrecionalidad la harían inconstitucional; o la entendemos como un enunciado más bien incompleto que no excluye a la SBIF de las limitaciones constitucionales generales a las potestades administrativas. Los desafíos de la segunda opción, sin embargo, son variados: identificar precisamente tales limitaciones en el contexto respectivo; concientizar a la SBIF de aquéllos; lograr su exigibilidad vía control jurisdiccional, etc.

En definitiva, el lenguaje excesivamente entusiasta del legislador presenta múltiples inconvenientes y debiera ser corregido hacia la mayor moderación y precisión. Tales problemas se repiten en muchos otros casos, y han dado lugar a la creación, vía norma administrativa, de un cúmulo de categorías, obligaciones e ilícitos administrativos que escapan al ámbito de acción constitucionalmente asignado al administrador ${ }^{28}$.

\footnotetext{
${ }^{27}$ Tribunal Constitucional (2003) rol № 389, considerandos vigésimo quinto y vigésimo sexto.

${ }^{28}$ Así, por ejemplo, encontramos que las superintendencias crean conceptos no contemplados en la ley como en la Norma de Carácter General No 210, emitida por la SVS, de 15 de enero de 2008, que modifica en lo pertinente a la Norma de Carácter General No 30, de 10 de noviembre de 1989, al tratar "la información relevante para la toma de decisiones financieras o de otra índole", la cual crea el concepto de "información de interés". Otro ejemplo consiste en las órdenes que emiten las superintendencias a los regulados para que designen a personal facilitador de la fiscalización y a sus suplentes, los cuales deberán cumplir una serie de requisitos (Circular IF No 50, emitida por la SS, de 23 de julio de 2007 y el Oficio Circular No 4 de la SCJ,
} 


\section{Obligación de declarar}

Diversos cuerpos normativos otorgan a las superintendencias la facultad de citar a declarar a personas relacionadas a los rubros fiscalizados ${ }^{29}$. Al margen de señalar que tal facultad podría exceder el ámbito netamente fiscalizador para introducirse en la esfera jurisdiccional, nos parece que su consagración legislativa nuevamente peca de excesiva amplitud y de omitir limitaciones fundamentales.

En primer término, no parece razonable señalar que la asistencia de las personas citadas sea obligatoria, a lo menos cuando son particulares y no funcionarios públicos, y menos aún que aquélla pueda exigirse compulsivamente (i.e. mediante la fuerza pública). Cabe recordar a este respecto que la citación obligatoria y compulsiva es una gran excepción en nuestro derecho, propia de los órganos jurisdiccionales en el marco de un proceso jurisdiccional. Es así como investigaciones tan fundamentales para nuestro Estado de Derecho como aquellas que llevan a cabo comisiones ad-hoc de la Cámara de Diputados, carecen de la facultad de convocar obligatoriamente a particulares (artículo 52 letra c) de la CP).

En segundo lugar, y considerando los elementos jurisdiccionales envueltos, tales citaciones deben someterse a ciertas limitaciones mínimas, aun cuando aquéllas no aparezcan expresamente en los cuerpos legales habilitantes. Destacamos entre ellas la facultad de concurrir y no declarar (artículo 93 letra g) del Código Procesal Penal) y el derecho de no auto-inculparse (artículo 19 No 7 letra f) de la CP; artículo 305 del Código Procesal Penal; artículo 8 No 2 letra g) de la Convención Americana sobre Derechos Humanos, y artículo 14 No 2 letra g) del Pacto Internacional de Derechos Civiles y Políticos). Si bien aquél se refiere específicamente sólo a causas criminales, creemos que es perfectamente aplicable a los procedimientos ante las superintendencias, toda vez que el criterio de clasificación es sustancial, no formal. En otras palabras, nos parece que una interpretación garantista de la CP nos obliga a entender que la prohibición del artículo 19 No 7 letra f) se aplica cuando los hechos en cuestión sean de tal naturaleza que puedan dar lugar a causas criminales, al margen de la investigación administrativa en curso (situación de no

de 10 de noviembre de 2006). En estos casos, si bien no existe habilitación legal específica para que las superintendencias obliguen a crear cargos dentro de las personas reguladas, se entendería incluida ésta dentro de las facultades genéricas de fiscalización. Cabe destacar que esta obligación impuesta por las superintendencias pareciera ser razonable siempre y cuando no implique una interferencia en la organización y administración de la empresa, facultad exclusiva del propietario.

${ }^{29}$ Considérese, por ejemplo, lo dispuesto en el artículo 18 inciso $1^{\circ}$ del Decreto con Fuerza de Ley No 3 de 1997 del Ministerio de Hacienda, Ley General de Bancos; el artículo $4^{\circ}$ letra h) del Decreto Ley No 3538 de 1980; el artículo 17 inciso $2^{\circ}$ del ARTÍ́CULO 6º de la Ley No 19.937 de 2004; el artículo 3º No $^{\circ} 17$ inciso $4^{\circ}$ de la Ley No 18.933 de 1990, y el artículo 42 No 14 de la Ley No 19.995 de 2005. 
difícil ocurrencia en el ámbito en estudio) ${ }^{30}$, y no sólo cuando se produzca en el ámbito formal de un procedimiento criminal.

A mayor abundamiento, debemos recordar la creciente aplicación de las garantías procesales penales al ámbito del derecho administrativo sancionatorio ${ }^{31}$, circunstancia que refuerza la aplicación de los límites antes señalados a las investigaciones y procedimientos desarrollados por las superintendencias.

\section{Narcotráfico y terrorismo}

Hemos detectado que estos temas, altamente sensibles, han dado lugar a una normativa de dudosa constitucionalidad. No cabe duda que la gran importancia de atacar estos males, así como la necesidad de contar con medios no tradicionales o extraordinarios para su detección, han redundado en el fortalecimiento de la fiscalización de entidades particularmente expuestas a su influjo, e.g., bancos y sociedades anónimas.

Entre los problemas detectados destaca la pasmosa generalidad de los preceptos legislativos habilitantes ${ }^{32}$, así como la dictación por parte de las superintendencias de normativa administrativa extremadamente impositiva, compleja, intrusiva e interferente con los derechos de los regulados. Así, por ejemplo, la Circular No 3.435 (2008) de la SBIF establece una serie de obligaciones a los bancos de recabar información; de investigar a sus bancos corresponsales, incluyendo "tomar conocimiento de los controles implementados para detectar operaciones de lavado de activos y financiamiento del terrorismo"; de "contar con las herramientas tecnológicas adecuadas, que le permitan desarrollar sistemas de alertas, con el propósito de identificar y detectar operaciones inusuales", etc. Por su parte, la Circular No 1809 (2006) de la SVS crea la clasificación de "Personas Expuestas Políticamente", quienes gatillan obligaciones de control para los regulados, así como responsabilidades para los mismos, en circunstancias que tal categoría de personas no es de creación legal. A su vez, la Circular No 3 (2007) de la SCJ impone la creación de procedimientos internos, obligaciones de capacitación y destinación de personal, entre otros.

\footnotetext{
${ }^{30}$ Esta doble penalización es altamente discutible. Véase AlCALDE (2003) pp. 224-239.

${ }^{31}$ Camila Boettiger realiza un completo análisis relativo a la jurisprudencia del TC y de la doctrina en relación al punto en cuestión Boettiger (2009) pp. 588-593. Véase también Aguerrea (2005) pp. 73-96.

32 Así, la Ley No 19.913 de 2003 impone la obligación de informar a diversas personas naturales y jurídicas de derecho privado. El artículo $3^{\circ}$ inciso $1^{\circ}$ extiende esta obligación a "informar sobre los actos, transacciones u operaciones sospechosas que adviertan en el ejercicio de sus actividades”, y el inciso $2^{\circ}$ del antedicho artículo define la operación sospechosa como "todo acto, operación o transacción que, de acuerdo con los usos y costumbres de la actividad de que se trate, resulte inusual o carente de justificación económica o jurídica aparente, sea que se realice en forma aislada o reiterada".
} 
En definitiva, nos parece que el celo del legislador y las superintendencias en combatir el narcotráfico y el terrorismo han dado lugar a excesos normativos. Si bien algunos de ellos fueron corregidos por el Tribunal Constitucional ${ }^{33}$, sobreviven algunos que exigen su regularización.

\section{FACULTADES NORMATIVAS}

\section{Naturaleza de las normas emitidas por las superintendencias}

Existe una discusión acerca de si las facultades normativas de las superintendencias se insertan en la potestad reglamentaria presidencial o constituyen una categoría diversa ${ }^{34}$. Coincidimos con la segunda postura (fundamentalmente porque el Presidente de la República no puede ejercer por sí mismo tales potestades, ni corregir o dejar sin efecto los actos dictados en su ejercicio por los superintendentes $^{35}$ ), de lo cual emanan consecuencias jurídicas de gran relevancia. En efecto, en nuestro sistema la única norma capaz de producir fuentes formales del derecho es la CP, y el texto de aquélla no reconoce una potestad normativa autónoma de las superintendencias. En consecuencia, se trata de una creación simplemente legal, la que, por lo tanto, es esencialmente limitada y en ningún caso puede extenderse a materias comprendidas en el dominio reservado al legislador. En otras palabras, y tal como lo ha señalado la CGR, se trata de una potestad que sólo puede aspirar a explicitar o explicar la ley, por lo que no puede imponer obligaciones ${ }^{36}$ ni crear facultades ${ }^{37}$. De esta forma, las normas dictadas en su virtud se distinguen de los reglamentos presidenciales, a los cuales quedan subordinadas, en las materias que expresamente señale la ley.

\footnotetext{
${ }^{33}$ El TC se ha pronunciado en contra del otorgamiento de facultades administrativas exorbitantes a organismos administrativos. Véase, entre otras, la sentencia rol 198 en relación al Consejo de Defensa del Estado TribunAL Constitucional (1995) rol No 198 y la sentencia rol No 389, relativa a la Unidad de Análisis Financiero Tribunal Constitucional (2003) rol No 389, considerandos vigésimo quinto y vigésimo sexto.

${ }^{34}$ En términos generales (i.e. relativos a los órganos administrativos autónomos en su conjunto), véase (SiLvA Bascuñan (2000b), p. 174 y Silva Cimma 1992, pp. 250-252). Específicamente sobre las normas emitidas por las superindentencias y su jerarquía, consúltese (CARMONA 1999, p. 12; GARCÍA 2009, pp. 341-342; EVANS EsPIŃEIRA (2006), p. 122).

${ }^{35}$ Cabe recordar que las Superintendencias son organismos descentralizados. Véase CARMONA (1999) p. 9.

${ }^{36} \mathrm{La}$ CGR ha rechazado la posibilidad que se creen obligaciones a particulares por cualquier fuente jurídica que no sea la ley Contraloría General de la República (2008) No 36737 y Contraloría General de la República (2008) No 2965. Cfr. Evans Espiñeira (2006) p. 120.

${ }^{37}$ La CGR ha negado la posibilidad de que existan potestades públicas que no tenga su origen en la ley. Contraloría General de la República (2008) No 35205 y Contraloría General de la República (2006) No 38949. Cfr. Silva Bascuñan (1997) p. 146.
} 
Reconocer un ámbito o jerarquía mayor a la regulación emanada de las superintendencias sería inconstitucional, aún frente a norma legal expresa. Ello por cuanto se trataría de una suerte de delegación del legislador de parte de sus potestades legislativas en las superintendencias, en circunstancias que aquellas facultades le son indisponibles por expresa voluntad del constituyente. En otras palabras, lo que el constituyente ha encargado al legislador, éste no puede delegarlo en terceros, ya que se subvertiría todo el complejo sistema de asignación de competencias, de frenos y contrapesos, diseñado por la CP. Tanto es así, que la única posibilidad de tal delegación por parte del legislador está cuidadosamente regulada y limitada en el artículo 64, y tiene por único beneficiario al Presidente de la República. Imposible pensar, por tanto, que el legislador tenga la libertad de delegar esas potestades en otra autoridad, y menos aún de hacerlo sin limitaciones de ninguna especie.

Algo similar ocurre con la facultad de dictar reglamentos, en cuanto normas obligatorias de carácter general llamadas a complementar la ley38. Sólo la CP puede otorgar tal potestad, toda vez que se vincula íntimamente al entramado constitucional de separación de funciones. Ese es el caso del Presidente de la República (artículos 32 y 35 de la CP) y de las Cámaras del Congreso Nacional (artículo 56 de la CP).

Es así como la CGR ha señalado claramente que no es lícito que circulares, oficios, etc., regulen materias propias de los reglamentos ${ }^{39}$, máxime cuando aquellas son normas que"(...) sólo tienen por objeto materializar la potestad de mando que corresponde a los jefes de servicio en relación con los funcionarios que les están subordinados, precisando la interpretación práctica que deben otorgar a las leyes y reglamentos que les corresponde aplicar en el ejercicio de sus labores, y que la referida potestad de mando no crea obligaciones para los particulares" 40.

\footnotetext{
${ }^{38}$ En cuanto al concepto de "reglamento" como fuente de derecho, véase (SilVA BASCUÑAN (2000b), pp. 125-126; Verdugo et ALII. 1999, pp. 93-94).

${ }^{39}$ Un excelente ejemplo lo constituye la Circular No 2, de 17 de abril de 2007, emitida por la SCJ, que "Imparte instrucciones a las sociedades operadoras acerca del procedimiento al que se someterán las solicitudes de modificación de proyectos autorizados". La CGR señala que en dicha circular se establecía "(...) normas orientadas a determinar los mecanismos a que deben ajustarse tanto la respectiva autoridad como las sociedades operadoras para obtener la aprobación anticipada de las modificaciones sustanciales de que se trata, indicando dicho acto previa clasificación de aquéllas, cuales son los órganos encargados de otorgar la respectiva anuencia y los requisitos a que los interesados deben ajustarse para obtenerla, incluido el aumento proporcional de las garantías, ya enunciado, además de la especificación de un sistema de registro de las variaciones no sustanciales, como manifestación del ejercicio de las facultades fiscalizadoras del servicio ocurrente". Lo anterior es rechazado por la CGR, ya que "(...) las aludidas disposiciones se encuentran destinadas a detallar los preceptos de la ley No 19.995, ya citada, que exigen la obtención de la autorización previa en examen, objetivo que, tal como establece el artículo $32 N^{o}$ 6, de la Carta Política, corresponde al ejercicio de la potestad reglamentaria que pertenece al Presidente de la República" Contraloría General de la República (2008) No 36737 y Contraloría General de la República (2008) No 2965.

${ }^{40}$ Contraloría General de la República (2008) No 36737.
} 
Más aún, cuando la ley ha encargado la regulación de una materia a un reglamento, aquél no puede delegar tal labor en las superintendencias y en los actos administrativos que aquéllas emiten ${ }^{41}$, cuestión que evidencia la clara división de competencias existente entre ambas clases de normas administrativas.

En definitiva, todas las regulaciones emitidas por las superintendencias son fruto de la potestad normativa que les concede expresamente el legislador, la que no se extiende ni a competencias legislativas, ni tampoco a la emisión de reglamentos.

\section{Las normas de carácter general}

Dentro de la diversidad conceptual de las normas emitidas por las superintendencias (circulares, oficios circulares, etc.), ha surgido una categoría específicamente asociada a estos organismos, denominadas NCG.

En términos prácticos, parece haberse entendido por las superintendencias y sus regulados que las NCG constituyen una suerte de normativa general o marco, destinada a regular extensivamente ciertas materias sujetas a la competencia normativa de las superintendencias. En este contexto, las demás normas emitidas por estos organismos (e.g., circulares), se referirían a aspectos no regulados en tales normas de carácter general, o a meras precisiones o desarrollos de aquéllas. En otras palabras, las NCG serían una suerte de "ley", complementada posteriormente por los demás actos normativos en calidad de "reglamentos", "decretos", etc. O si se prefiere, las NCG serían los "reglamentos", y las otras meras normas administrativas inferiores y subordinadas a las NCG.

La visión antes mencionada se fundamenta en razones de texto legal. Es así como diversos preceptos legales habilitan a las superintendencias a dictar NCG, ya sea en esos términos precisos o en otros similares (e.g., "normas de aplicación general", "reglas de carácter general") 42.

\footnotetext{
${ }^{41}$ Así, por ejemplo, la CGR devolvió un Decreto del Ministerio de Hacienda que aprobó el reglamento de la Ley No 18.815 de 1989, el cual otorgó una atribución a la SVS en materia de plazos, debiendo haber sido esta norma aquella que los estableciera "(...) art/30 inc/1 otorga a la superintendencia la atribución de determinar los plazos para regularizar los excesos de inversión, lo que es improcedente acorde Ley No 18815 art/12 que dispone que el reglamento establecerá los plazos en que deberá procederse para tal efecto" CONTRALORÍA GENERAL DE LA RePública (1989) No 32689.

${ }^{42}$ Véase los artículos 15 inciso $1^{\circ}, 16$ inciso $3^{\circ} \mathrm{y}$ final, 16 bis, 21, 35 inciso final, 36 inciso 3º, 43, 70 a), 71 inciso $2^{\circ}, 78$, y 81 inciso $2^{\circ}$ del Decreto con Fuerza de Ley No 3 de 1997 del Ministerio de Hacienda, Ley General de Bancos; los artículos 137 inciso $1^{\circ}, 52$ inciso $2^{\circ}, 24$ inciso $2^{\circ}, 29$ inciso $1^{\circ}, 65$ inciso $4^{\circ}, 144$ inciso $1^{\circ}, 8$ inciso $1^{\circ}, 26$ letra i), 26 inciso final, 32 inciso $1^{\circ}, 71$ inciso $1^{\circ}, 104$ inciso $2^{\circ}, 131$ inciso $2^{\circ}, 155$ letra a), 183 inciso $3^{\circ}, 189$ inciso $1^{\circ}$ y $3^{\circ}, 197$ inciso $1^{\circ}$ y 203 letra k) de la Ley $N^{\circ} 18.045$ de 1981 ; el artículo $1^{\circ}$ inciso $2^{\circ}$ la Ley No $^{\circ} 18.876$ de 1989; el artículo $2^{\circ}$ No $^{\circ}$ de la Ley $N^{\circ} 18.046$ de 1981 ; los artículos $1^{\circ}$ letra f) No 2, 3o letra e) y k) del Decreto con Fuerza de Ley No 251 de 1931; los artículos $6^{\circ} \mathrm{No}^{\circ} .1$ y $4,8^{\circ}$ inciso $2^{\circ}$ y 18 inciso $2^{\circ}$ del ARTÍ́CULO $6^{\circ}$ de la Ley $N^{\circ} 19.937$ de 2004; los artículos $22^{\circ}$ inciso $14^{\circ}, 22^{\circ}$ inciso $8^{\circ}, 38$ ter inciso $2^{\circ}$ de la Ley No 18.933 de 1990, y el artículo 42 oo 7 de la Ley No 19.995 de 2005.
} 
Creemos, sin embargo, que este entendimiento, y la práctica que de él se ha derivado, son erróneos. Tal y como señalábamos en la letra precedente, todas las normas emitidas por las superintendencias tienen rango inferior a la ley y al reglamento. Adicionalmente, cualquier jerarquía entre ellas carece de sustento en la Constitución e incluso en la Ley No 19.880 de 2003, de Procedimientos Administrativos. Al respecto, la sola nomenclatura utilizada por el legislador no permite deducir la creación de una categoría especial de normas. En efecto, por normas o reglas generales debemos entender justamente eso, i.e., aquellas dirigidas a la generalidad de los regulados sobre circunstancias de común ocurrencia, en oposición a las normativas particulares, destinadas a una situación específica.

En consecuencia, las normas de carácter general no gozan de una jerarquía mayor a las circulares y demás regulaciones de origen administrativo. A lo más existe una diferencia en cuanto al carácter más o menos general de sus contenidos. Por tanto, sin desmerecer los ideales de orden de las superintendencias en esta materia, aquellos deben ser vistos como mera disciplina o auto-regulación en el ejercicio de sus potestades normativas.

\section{Prohibición de actividades económicas}

Si bien existe en nuestro país una gran discusión doctrinaria y jurisprudencial respecto de las facultades de la Administración para regular la actividad económi$\mathrm{Ca}^{43}$, pareciera existir mayor consenso en que aquellas de ningún modo alcanzan a la prohibición de las mismas ${ }^{44}$.

Sin embargo, en nuestra investigación hemos descubierto diversas situaciones en que las superintendencias, ya sea directamente, ya sea a través de la imposición de ciertas obligaciones, impone prohibiciones a la actividad económica de sus regulados. Así, por ejemplo, ocurre con la prohibición impuesta a las instituciones financieras de exhibir en sus locales premios ofrecidos a sus clientes (Circular No 3227 (2003) de la SBIF) o con la prohibición del artículo $7^{\circ}$ del Decreto Supremo No 950 de 1928 del Ministerio de Hacienda "a toda imprenta o empresa periodística que no sea la encargada por la Cámara de Comercio de Chile” de publicar ciertos datos relativos a letras de cambio y pagarés.

\section{Sustento normativo en acuerdos del Banco Central}

Hemos descubierto que algunas normas emitidas por las superintendencias, en particular la SBIF, invocan como fundamento legal de sus competencias acuerdos

${ }^{43}$ Véase, entre otros (Soto Kloss (2009), pp. 365-376; Aróstica (2001), pp. 81-84; Fermandois (2006), pp. 156-157; Silva Cimma (2001), p. 20).

${ }^{44}$ (Aróstica (2001), pp. 77-81; Fermandois (2006), p. 139; Evans de la Cuadra (1999), pp. 140-141). 


\section{del Banco Central ${ }^{45}$. Tal situación es evidentemente irregular. Como señalábamos} previamente, el Principio de Juridicidad exige que toda potestad administrativa tenga como fundamento una norma legal o constitucional habilitante. Los cimientos de tal principio hunden sus raíces en consideraciones ontológicas, deontológicas y democráticas que hoy resultan incuestionables ${ }^{46}$.

Ahora bien, los acuerdos del Banco Central no constituyen ley bajo ningún respecto: no son obra de los co-legisladores reconocidos por la CP; no siguen el procedimiento único establecido en la CP para la tramitación de normas legales; no son objeto de control de constitucionalidad; no comparten la majestad democrática de la ley ni su legitimidad procedimental; no otorgan la certeza jurídica de una norma legal, y están indiscutiblemente sometidos a la Ley No 18.840 de 1989, Orgánica Constitucional del Banco Central.

La facultad otorgada por la CP al Banco Central de adoptar acuerdos, por tanto, no constituye una potestad legislativa, sino que una potestad reglamentaria, distinta a la presidencial ${ }^{47}$. Su naturaleza se asimila a la potestad reglamentaria de las Cámaras"s, sobre la cual el TC ha señalado explícitamente que no gozan "de la fuerza jurídica de la jerarquía legal, a la que, a la inversa, quedan subordinados" 49

\footnotetext{
${ }^{45}$ Un ejemplo es la Circular No 3417, de 10 de enero de 2008, emitida por la SBIF, la cual trata de las cuentas de ahorro, la superintendencia al tratar las disposiciones generales sólo alude al Compendio de Normas Financieras del Banco Central de Chile (Capítulos III E.1, 2, 3 y 4). El caso es especialmente llamativo ya que la superintendencia individualiza las condiciones que deben cumplir los contratos de apertura de diversas clases de "cuentas de ahorro".

${ }^{46}$ El Principio de Juridicidad se puede definir como la "sujeción integral a derecho de los órganos del Estado tanto en su ser como en su obrar" Sото KLOss (1996) p. 24. En cuanto a sus alcances y explicaciones (pp. 47-56), a los fundamentos históricos (pp. 114-145), políticos (pp. 145-154) y jurídicos (pp. 154-156) véase Sото KLoss (1996) páginas señaladas. En cuanto al principio de legalidad como elemento integrante del Estado Formal de derecho y su relevancia en el Estado Social y Democrático de Derecho, véase Verdugo ET ALII. (2002) p. 137; en su sentido originario relativo a la "forma legítima de expresión de la voluntad general” véase García de EnTERría y FERnÁNDEZ (2006) pp. 437-440.

${ }^{47}$ Aun cuando los acuerdos del Banco Central están reconocidos en la CPR, en su artículo 109 inciso $4^{\circ}$ y en la Ley No 18.840 de 1989, como señala Arturo Fermandois, "los acuerdos no son formalmente leyes. porque no han sido sometidos al proceso constitucional de formación de la ley, sin perjuicio de no serlo en razón de las materias que eventualmente regulen. Al mismo tiempo, los acuerdos no pertenecen a la potestad reglamentaria presidencial, ni autónoma ni de ejecución (...) los acuerdos del Banco Central son en definitiva, el ejercicio material de la potestad normativa que le cabe como ente constitucional autónomo, y deben subordinarse a la ley" Fermandois (1995) pp. 386-387.

${ }^{48}$ Silva Bascuñán señala que éstos “(...) constituyen su estatuto interno (...) los que no sólo detallan y complementan las reglas principales determinadas por el constituyente o el legislador, y en cuya ejecución deben intervenir, sino que contribuyen a interpretar o a dar sentido a muchas de ellas" cfr. SILVA BASCUÑÁN (2000a) pp. 23-25.

49 Alejandro Silva Bascuñán citado en Tribunal Constitucional (2008) rol No 1216, considerando décimo.
} 
y que "Resulta evidente que por su propia naturaleza son completamente distintas a un cuerpo legal"so.

En consecuencia, los acuerdos del Banco Central, al no tener naturaleza ni jerarquía legal, no pueden considerarse como norma legal habilitante de potestades administrativas. Por lo tanto, las circulares, NCG, etc., dictadas por las superintendencias sobre la base exclusiva de tales acuerdos, vulneran el Principio de Juridicidad consagrado en el artículo $7^{\circ}$ de la CP.

\section{FACULTADES SANCIONATORIAS Y JURISDICCIONALES}

La constitucionalidad de atribuir potestades sancionatorias y jurisdiccionales a las superintendencias ha sido objeto de gran controversia en la dogmática nacional ${ }^{51}$. Sin embargo, aún asumiendo que tal asignación de facultades sea constitucional, incluso en su vertiente arbitral o mediadora ${ }^{52}$, existen una serie de situaciones que claramente no son aceptables en nuestro ordenamiento jurídico. Mencionaremos sumariamente algunas de ellas:

\section{Diseño de sanciones}

En ciertas ocasiones las sanciones se construyen en términos genéricos, residuales y de gran amplitud. Así, por ejemplo, el artículo 46 de la Ley No 19.995 de 2005, de Casinos, señala que "Las infracciones a esta ley que no tengan señalada una sanción especial serán penadas con multa a beneficio fiscal de tres a noventa unidades tributarias mensuales". Observamos que se trata de una norma residual, cuestión que fácilmente puede atentar contra las finalidades de la pena y de la norma infringida. Más aún, podría afectar la proporcionalidad que debe existir entre la infracción y la sanción. Si bien en este caso ese peligro pareciera atenuarse en razón de la extrema versatilidad de la pena, se trata sólo de una seguridad aparente. En efecto, el hecho de que la pena pueda variar en un 3000\%, sin que se ofrezcan criterios que sirvan de elementos reglados para su correcto ejercicio, nos debe causar la natural aprensión que surge frente a potestades públicas excesivamente

\footnotetext{
${ }^{50}$ Tribunal Constitucional (2008) rol No 1216, considerando undécimo.

${ }^{51}$ Sobre potestades sancionatorias y jurisdiccionales de las superintendencias, véase (GARCíA (2009), pp. 354366; Aróstica (2008), pp. 170-173; CARMONA (1999), pp. 18-20, 23-24 y 26-32. En relación a la potestad sancionatoria y jurisdiccional realizada por organismos de la Administración del Estado en general, véase entre otros a Soto Kloss (2009), pp. 403-419; Boettiger (2009), pp. 580-582; Román (2008), pp. 117-120; CAMAcho (2007), pp. 12-23; Aguerrea (2005), pp. 73-96; Alcalde (2003), pp. 224-239).

${ }^{52}$ Véase, por ejemplo, los artículos 48 y 124 inciso 4o del Decreto con Fuerza de Ley No 3 de 1997 del Ministerio de Hacienda, Ley General de Bancos; el artículo $3^{\circ}$ letra i) del Decreto con Fuerza de Ley No 251 de 1931; los artículos $8^{\circ}$ y 12 No10 del ARTÍ́CULO 6º de la Ley o 19.937 de 2004, y los artículos 33 y 43 de la Ley No 18.933 de 1990.
} 
discrecionales. Otro caso similar es el contemplado en el artículo 19 del Decreto con Fuerza de Ley No 3 de 1997 del Ministerio de Hacienda, Ley General de Bancos, la que señala que los bancos que "incurrieren en alguna infracción a la ley que las rige, a sus leyes orgánicas, a sus estatutos o a las órdenes legalmente impartidas por el superintendente, que no tenga señalada una sanción especial, podrán ser amonestadas, censuradas o penadas con multa hasta por una cantidad equivalente a cinco mil unidades de fomento". Nuevamente nos hayamos frente a una sanción residual de enorme variabilidad.

\section{Defectos procedimentales}

Existen una serie de normas que limitan el derecho a la acción, a la defensa, y en general, al procedimiento justo y racional o debido proceso. Nos referimos a cuestiones tales como los procedimientos administrativos sumamente incompletos, casos de solve et repete $e^{53}$ (cuya inconstitucionalidad ya fue declarada por el TC en otro ámbito ${ }^{54}$; la no suspensión de los efectos del acto reclamado ${ }^{55}$; presunciones de responsabilidad ${ }^{66}$; sanciones como título ejecutivo ${ }^{57}$; capacidad de adoptar "medidas precautorias" 58 ; establecimiento de sanciones por incumplimiento de sus propias circulares y similares ${ }^{59}$, entre otras. Adicionalmente, cabe recordar que muchas superintendencias han reglamentado los procedimientos de reclamación de sus actos mediante circulares y similares ${ }^{60}$. Si bien esto podría intentar justifi-

${ }^{53}$ E.g., artículo 22 inciso $1^{\circ}$ del Decreto con Fuerza de Ley No 3 de 1997 del Ministerio de Hacienda, Ley General de Bancos, y artículo 30 inciso 2o del Decreto Ley No 3538 de 1980.

54 Tribunal Constitucional (2009) rol No 1345. Creemos que al declarar la inconstitucionalidad del inciso primero, frase segunda del artículo 171 del Código Sanitario "Para dar curso a ellos se exigirá que el infractor acompañe el comprobante de haber pagado la multa" y en virtud a la jurisprudencia constitucional de los últimos dos años (entre otros en los fallos véase Tribunal Constitucional (2008) rol No 792; (2008) rol No 946; (2008) rol No 968; (2008) rol No 1046; (2008) rol No 1061; (2009) rol No 1253 (2009) rol No 1262; (2008) rol No 1279, entre otros) que declara sostenidamente la ilegitimidad del mecanismo en materia laboral y sanitaria, es altamente probable que el TC se pronuncie en igual sentido respecto a los casos citados en nota precedente.

${ }^{55}$ Véase, por ejemplo, el artículo 42 I de la Ley № 18.933 de 1990.

${ }^{56}$ Artículo 22 inciso final del Decreto con Fuerza de Ley No 707 de 1980.

${ }^{57}$ Artículo $7^{\circ}$ incisos $1^{\circ}$ y $2^{\circ}$ del ARTíCULO 6o de la Ley No 19.937 de 2004.

${ }^{58}$ Artículo 6o No 9 del ARTíCULO 6o de la Ley No 19.937 de 2004.

${ }^{59}$ EVAns Espiñeira (2006) p. 124.

${ }^{60}$ Véase, por ejemplo, el artículo 18 inciso 20 del ARTíCULO 60 de la Ley No 19.937 de 2004, el cual señala, en cuanto a los procedimientos que dan lugar por los reclamos de los afiliados y beneficiarios de FONASA, ISAPRES y prestadores de salud, que "La Superintendencia fijará, a través de normas de general aplicación, el procedimiento (...)". La Circular IF No 4, de 6 de mayo de 2005, emitida por la SS en cumplimiento al mandato del precepto legal transcrito, fija los requisitos del reclamo respecto a su: a) recepción por la entidad 
carse en cuanto mecanismo de autolimitación y transparencia, es una práctica que resulta completamente inconstitucional si adoptamos la postura que señala que las superintendencias ejercen jurisdicción ${ }^{61}$. En efecto, esta última se desplegaría no sólo violando normas constitucionales relacionadas a la independencia e imparcialidad constitucional del tribunal (artículos $4^{\circ}$ y 76 de la CP), sino también el artículo 19 No 3 (derecho a un procedimiento racional y justo), y el cuidadoso entramado contemplado en la CP para la elaboración de normas procedimentales (i.e., mediante ley orgánica y el quórum que ello implica, previo informe de la Corte Suprema, y sujetas a revisión obligatoria ex-ante de constitucionalidad por parte del Tribunal Constitucional).

\section{Conclusiones}

1. Tanto la normativa emitida por las superintendencias como los preceptos legales que le sirven de fundamento sufren de diversos vicios de constitucionalidad. Tales problemas varían en su tipo y gravedad.

2. Algunas anomalías son "estructurales", su aplicación es genérica y exigen una solución radical. Entre ellas destaca el intento de limitación de las facultades constitucionales de la CGR, la existencia de procedimientos sancionatorios carentes de las garantías procesales mínimas, y la consagración de sanciones mal diseñadas y peor descritas.

3. Otros problemas dicen relación con malas prácticas legislativas, tales como la amplitud de las normas habilitantes y la falta de identificación clara de los motivos de la regulación. Aquéllos debieran ser de una -relativamente- fácil corrección.

4. También es posible identificar excesos por parte de las superintendencias que redundan en la vulneración de los derechos de los regulados (e.g., imposición de plazos irrazonables o muy demandantes).

reclamada b) registro c) expediente que ha de mantenerse d) la respuesta y su plazo e) la notificación y sus plazos f) la revisión de la respuesta por la superintendencia g) el archivo de la respuesta. Algo más grave ocurre con la Circular IF No 59, de 18 de enero de 2008, la cual "en virtud de las atribuciones y facultades legales que le confiere el D.F.L. No 1, de 2005, de Salud y la Ley No 19.966 de 2004" trata el "procedimientos de sanciones de la Intendencia de Fondos y Seguros Previsionales de Salud". Al regular estos procedimientos la Circular elabora, entre otros, "principios generales del procedimiento de sanciones", las etapas del procedimiento sancionatorio, determinando múltiples etapas ("la etapa de investigación", "notificaciones", "formulación de cargos", "descargos", término probatorio", "cierre de la investigación y evaluación de antecedentes", etc.). Ni las atribuciones para regular este procedimiento, ni la creación de estos puntos específicos no aparecen en los cuerpos legales invocados.

${ }^{61}$ (CAmacho (2007), pp. 13-14; Vergara (2005), p. 257; Rodríguez (1987), p. 133). 
5. La doctrina y la jurisprudencia son parcialmente responsables de algunos de los problemas detectados, particularmente aquellos que se vinculan a la falta de una dogmática clara y desarrollada en estos tópicos (e.g., rango y contenido de las normas emitidas por las superintendencias).

6. La gran mayoría de las anomalías estudiadas son comunes a todas las superintendencias analizadas, independientemente de su antigüedad o posición de influencia.

7. La supremacía constitucional exige corregir las anomalías identificadas. Que algunas de ellas sean de larga data; que obedezcan a un fin loable, o que sean la excepción a la regla no son argumentos constitucionalmente aceptables para mantener tales anomalías, menos aún en momentos en que se considera crear nuevas superintendencias y reforzar algunas de las existentes.

\section{BiBLIOGRAFÍA \\ LIBROS Y ARTÍCULOS}

Aguerrea Mella, Pedro (2005): "Límites procesales a las potestades sancionatorias de la administración en la jurisprudencia del Tribunal Constitucional" en Conferencias Santo Tomás de Aquino. Sanciones Administrativas y derechos Fundamentales: regulación y nuevo intervencionismo (Santiago, Universidad Santo Tomás), pp. 73-96.

Alcalde Rodríguez, Enrique (2003): Los Principios Generales del Derecho su función de garantía en el derecho público y privado chileno (Santiago, Ediciones Universidad Católica de Chile).

Aróstica Maldonado, Iván (2008): "Chile always surprising: ¿sanciones sobre la marcha?”, en Ius Publicum, (No 21), pp. 170-173.

Aróstica Maldonado, Iván (2006): "Los dictámenes y la interpretación de la ley en sede administrativa”, en Actualidad Jurídica (Año VII, No 14), pp. 149-160.

Aróstica Maldonado, Iván (2001): Derecho Administrativo Económico (Santiago, Universidad Santo Tomás).

Boettiger Philipps, Camila (2009): "El derecho administrativo sancionador en la jurisprudencia del Tribunal Constitucional”, en Actualidad Jurídica, (Año X, No 20) Tomo II, pp. 577-596.

Camacho Cepeda, Gladys (2007): "La legitimidad de la Potestad Administrativa Sancionadora" en Revista de Derecho Público, Vol. 69 (No 2), pp. 9-23.

CAmacho Cepeda, Gladys (2005): "La problemática de la potestad normativa de las superintendencias", en Actas XXXIV Jornadas de Derecho Público (Santiago, LexisNexis), pp. 423-432. 
CARMOna SANTANDER, Carlos (1999): Una aproximación general sobre las superintendencias desde la perspectiva del derecho, apuntes de clases.

Evans de la Cuadra, Enrique (1999): Los Derechos Constitucionales (2a edición, Santiago, Editorial Jurídica de Chile) Tomo III.

Evans Espiñeira, Eugenio (2006): "Control de Constitucionalidad de la normatividad regulatoria de las actividades económicas", en Revista de Derecho Administrativo Económico (No 16), pp. 111-128.

Fermandois Vöhringer, Arturo (2006): Derecho Constitucional Económico (2a edición, Santiago, Ediciones Pontificia Universidad Católica de Chile).

Fermandois VÖHringer, Arturo (2005): "Efecto vinculante de las sentencias del Tribunal Constitucional: ¿mito o realidad”, en Zúniga Urbina, Francisco (2005) Reforma Constitucional, pp. 685-696.

Fermandois Vöhringer, Arturo (1995): "Naturaleza jurídica de los acuerdos del Banco Central de Chile y su conflicto con la Ley de Quiebras", en Revista Chilena de Derecho, Vol. 22 (No3), pp. 365-387.

García de Enterría, Eduardo y Fernández, Tomás Ramón (2006): Curso de Derecho Administrativo (13 $3^{\text {a }}$ edición, Navarra, Thomson Civitas) Tomo I.

Galetovic, Alexander y Sanhueza, Ricardo (2002): "Regulación de Servicios Públicos: ¿Hacia dónde debemos ir?”, en Estudios Públicos (No 85), pp. 101-137.

García García, José Francisco (2009): “¿Inflación de superintendencias? Un diagnóstico crítico desde el derecho regulatorio”, en Actualidad Jurídica, (Año X, No 19) Tomo I, pp. 327-371.

Rodríguez Collao, Luis (1987): "Bases para distinguir entre infracciones criminales y administrativas", en Revista de Derecho (Universidad Católica de Valparaíso) (Vol. 11), pp. 117-163.

RomÁn Cordero, Cristián (2008): "Derecho Administrativo Sancionador: ¿jer o no ser? he ahí el dilema”, en Pantoja BauzÁ, Rolando (Coord.) Derecho Administrativo 120 años de cátedra, pp. 107-141.

Romero GuZMÁn, Juan José (2005): “¿Cuándo hay un buen sistema regulatorio? Criterios de legitimidad” en Actas XXXIV Jornadas de Derecho Público (Santiago, LexisNexis), pp. 539-554.

Silva Bascuñan, Alejandro (2000a): Tratado de Derecho Constitucional. Bases generales, composición y atribuciones del Congreso y de las Cámaras. Estatuto de la función parlamentaria (2a edición, Santiago, Editorial Jurídica de Chile) Tomo VI.

Silva Bascuñan, Alejandro (2000b): Tratado de Derecho Constitucional. Gobierno (2a edición, Santiago, Editorial Jurídica de Chile) Tomo V. 
Silva Bascuñán, Alejandro (1997): Tratado de Derecho Constitucional. Bases de la institucionalidad, nacionalidad y ciudadanía, justicia electoral (2a edición, Santiago, Editorial Jurídica de Chile) Tomo IV.

Silva Cimma, Enrique (2001): Derecho Administrativo Chileno y Comparado. Actos, Contratos y Bienes (Santiago, Editorial Jurídica de Chile).

Silva Cimma, Enrique (1992): Derecho Administrativo Chileno y Comparado. Introducción y fuentes (4a edición, Santiago, Editorial Jurídica de Chile).

Sото KLoss, Eduardo (2009): Derecho Administrativo. Temas Fundamentales (Santiago, LegalPublishing).

Soто Kloss, Eduardo (1996): Derecho Administrativo. Bases Fundamentales. El Principio de Juridicidad (Santiago, Editorial Jurídica de Chile) Tomo II.

Verdugo et Alit. (2002): Derecho Constitucional (2a edición, Santiago, Editorial Jurídica de Chile) Tomo I.

Verdugo et alli. (1999): Derecho Constitucional (2a edición, Santiago, Editorial Jurídica de Chile) Tomo II.

Vergara Blanco, Alejandro (2005): "El contencioso administrativo en materia eléctrica: naturaleza jurisdiccional de las funciones del "Panel de Expertos", en Ferrada Bórquez, Juan Carlos (coord.), La justicia administrativa (Santiago, LexisNexis), pp. 241-270.

\section{JURISPRUDENCIA CONSTITUCIONAL}

Tribunal Constitucional (2009): rol No 1345, "Pronunciamiento de oficio sobre la inconstitucionalidad de las expresiones: [Para dar curso a ellos se exigirá que el infractor acompañe el comprobante de haber pagado la multa], contenidas en el inciso primero del artículo 171 del Código Sanitario", 25 de mayo de 2009 [fecha de consulta: 24 de noviembre de 2009]. Disponible en: http:// www.tribunalconstitucional.cl/index.php/sentencias/view/1146

Tribunal Constitucional (2009): rol No 1262, "Requerimiento de inaplicabilidad por inconstitucionalidad de Sociedad de Servicios y Asesorías Swan (Chile) S.A. respecto de la parte final del inciso primero, del artículo $171 \mathrm{del}$ Código Sanitario, en causa Rol 26.220-2008 del Décimo Sexto Juzgado Civil de Santiago, caratulada [Sociedad de Servicios y Asesorías SWAN S.A. con Secretaría Regional Ministerial de Salud de la Región Metropolitana]", 2 de abril de 2009 [fecha de consulta: 24 de noviembre de 2009]. Disponible en: http://www.tribunalconstitucional.cl/index.php/sentencias/view/1118

Tribunal Constitucional (2008): rol No 1279, "Requerimiento de inaplicabilidad por inconstitucionalidad de Manuel Enrique Valdés Valdés en su 
calidad de administrador de la Comunidad Edificio Santiago Centro y en su representación, respecto de la parte final del inciso primero, del artículo 171 del Código Sanitario, en causa Rol C-25623-2008, caratulada "Comunidad Edificio Santiago Centro con Secretaría Regional Ministerial de Salud de la Región Metropolitana y Fisco de Chile", del Segundo Juzgado Civil de Santiago y actualmente en apelación ante la Corte de Apelaciones de Santiago" 2 de abril de 2009 [fecha de consulta: 24 de noviembre de 2009]. Disponible en: http://www.tribunalconstitucional.cl/index.php/sentencias/view/1117

Tribunal Constitucional (2009): rol No 1253, "Requerimiento de inaplicabilidad deducido por Arco Arquitectura y Construcción Limitada respecto del inciso primero del artículo 171 del Código Sanitario, en la causa Rol 3240-2008, caratulada [ARCO ARQUITECTURA Y CONSTRUCCIÓN LIMITADA CON SECRETARÍA REGIONAL MINISTERIAL DE SALUD DE VALPARAÍSO] del Tercer Juzgado Civil de Valparaíso", 21 de enero de 2009 [fecha de consulta: 24 de noviembre de 2009]. Disponible en: http:// www.tribunalconstitucional.cl/index.php/sentencias/view/1094

Tribunal Constitucional (2008): rol No 1061, "Requerimiento de inaplicabilidad de Hernán Pfeifer Frenz, Paulina Alegría Madrid y Carmen Polanco Lazo respecto de la segunda frase, del inciso primero, del artículo 171 del Código Sanitario, en causa caratulada [Pfeifer Frenz, Hernán, y otras con Instituto de Salud Pública] Rol C-7770-2008, del 11º Juzgado Civil de Santiago", 28 de agosto de 2008 [fecha de consulta: 24 de noviembre de 2009]. Disponible en: http://www.tribunalconstitucional.cl/index.php/sentencias/view/1001

Tribunal Constitucional (2008): rol No 1046, "Requerimiento de inaplicabilidad de Sociedad Sergio Andrés Concha San Martín y Otro respecto de la parte final del inciso primero del artículo 171 del Código Sanitario, en la causa caratulada [Concha San Martín, Sergio Andrés, con Fisco], de la Corte de Apelaciones de Concepción”, 22 de julio de 2008 [fecha de consulta: 24 de noviembre de 2009]. Disponible en: http://www.tribunalconstitucional. cl/index.php/sentencias/view/971

Tribunal Constitucional (2008): rol No 1051, "Control de constitucionalidad del proyecto de ley, aprobado por el Congreso Nacional, sobre acceso a la información pública", 10 de julio de 2008 [fecha de consulta: 24 de noviembre de 2009]. Disponible en: http://www.tribunalconstitucional.cl/index.php/ sentencias/view/969

Tribunal Constitucional (2008) rol No 968, "Requerimiento de inaplicabilidad deducido por Asesoría y Servicio Empresarial Limitada respecto del inciso tercero del artículo 474 del Código del Trabajo, en la causa Rol No 806-07, 
caratulada [ASESORÍA Y SERVICIO con DIRECCIÓN DEL TRABAJO] del 50 Juzgado de Letras del Trabajo de Santiago", 10 de julio de 2008 [fecha de consulta: 24 de noviembre de 2009]. Disponible en: http://www.tribunalconstitucional.cl/index.php/sentencias/view/970

Tribunal Constitucional (2008) rol No 946, "Requerimiento de inaplicabilidad deducido por FM Seguridad S.A. respecto del inciso tercero del artículo 474 del Código del Trabajo, en la causa Rol No 757-07, caratulada [FM SEGURIDAD S.A. con DIRECCIÓN REGIONAL DEL TRABAJO] del $8^{\circ}$ Juzgado de Letras del Trabajo de Santiago", 1 de julio de 2008 [fecha de consulta: 24 de noviembre de 2009]. Disponible en: http://www.tribunalconstitucional. cl/index.php/sentencias/view/968

Tribunal Constitucional (2008): rol No 1216, "Requerimiento de diputados para que se declare la inconstitucionalidad de la declaración de admisibilidad del proyecto en virtud del cual se [modifica(n) los artículos 66 y 203 del Reglamento de la Cámara de Diputados, con el objeto de permitir que las sesiones de Sala y de Comisiones puedan celebrarse en la ciudad de Santiago y otros lugares que indica]", 30 de octubre de 2008 [fecha de consulta: 24 de noviembre de 2009]. Disponible en: http://www.tribunalconstitucional.cl/ index.php/sentencias/view/1035

Tribunal Constitucional (2008): rol No 1051, "Control de constitucionalidad del proyecto de ley, aprobado por el Congreso Nacional, sobre acceso a la información pública", 10 de julio de 2008 [fecha de consulta: 24 de noviembre de 2009]. Disponible en: http://www.tribunalconstitucional.cl/index.php/ sentencias/view/969

Tribunal Constitucional (2008): rol No 1032, "Control de constitucionalidad del proyecto de ley aprobado por el Congreso Nacional, [que crea el sistema de pensiones solidarias, modifica la institucionalidad para tal efecto, incorpora cambios al sistema de pensiones del decreto ley No 3.500 de 1980 y materias relacionadas]", 4 de marzo de 2008 [fecha de consulta: 24 de noviembre de 2009]. Disponible en: http://www.tribunalconstitucional.cl/index.php/ sentencias/view/848

Tribunal Constitucional (2008): rol No 792, "Requerimiento de inaplicabilidad presentado por Hernán Pfeifer Frenz y Paulina Alegría Madrid y Carmen Polanco Lazo, respecto de la segunda frase del inciso primero del artículo 171 del Código Sanitario, en los autos caratulados [Pfeifer Frenz con Instituto de Salud Pública], Rol 14980-2006, en el 11º Juzgado Civil de Santiago", 3 de enero de 2008 [fecha de consulta: 24 de noviembre de 2009]. Disponible en: http://www.tribunalconstitucional.cl/index.php/sentencias/view/728 
Tribunal Constitucional (2003): rol No 389, "Control de constitucionalidad respecto del proyecto de ley que crea la unidad de análisis financiero y modifica el Código Penal en materia de lavado y blanqueo de activos", 28 de octubre de 2003 [fecha de consulta: 24 de noviembre de 2009]. Disponible en: http:// www.tribunalconstitucional.cl/index.php/sentencias/view/231

Tribunal Constitucional (1995): rol No 198, "Control de constitucionalidad respecto del proyecto de ley que sanciona el tráfico ilícito de estupefacientes y sustancias sicotrópicas y sustituye la Ley $\mathrm{N}^{\circ} 18.403$ ”, 4 de enero de 1995 [fecha de consulta: 01 de diciembre de 2009]. Disponible en: http://www. tribunalconstitucional.cl/index.php/sentencias/view/418

Tribunal Constitucional (1990): rol No 92, "Control de constitucionalidad respecto del proyecto de ley que crea la Superintendencia de Instituciones de Salud Previsional, dicta normas para el otorgamiento de prestaciones por Isapres y deroga el D.F.L. No 3, de salud, de 1981”, 15 de enero de 1990 [fecha de consulta: 24 de noviembre de 2009]. Disponible en: http://www. tribunalconstitucional.cl/index.php/sentencias/view/520

\section{JURISPRUDENCIA ADMINISTRATIVA}

Contraloría General de la República (2009): Dictamen No 35494, 7 de julio de 2009 [fecha de consulta: 24 de noviembre de 2009]. Disponible en: http:// www.contraloria.cl/LegisJuri/DictamenesGeneralesMunicipales.nsf/FormIm presionDictamen?OpenForm\&UNID=59AB5D9BAAA5E66A842575EF00 57EB5B

Contraloría General de la República (2009): Dictamen No 28131, 29 de mayo de 2009 [fecha de consulta: 24 de noviembre de 2009]. Disponible en: http://www.contraloria.cl/LegisJuri/DictamenesGeneralesMunicipales.nsf/F ormImpresionDictamen?OpenForm\&UNID=1EAD886CA1D623618425 75CA0058C4E8

Contraloría General de la República (2008): Dictamen No 36737, 6 de agosto de 2008 [fecha de consulta: 24 de noviembre de 2009]. Disponible en: http:// www.contraloria.cl/LegisJuri/DictamenesGeneralesMunicipales.nsf/FormIm presionDictamen?OpenForm\&UNID=6C5CE4DF814382D3842574A200 67E706

Contraloría General de la República (2008): Dictamen No 35205, 29 de julio de 2008 [fecha de consulta: 24 de noviembre de 2009]. Disponible en: http://www.contraloria.cl/LegisJuri/DictamenesGeneralesMunicipales.nsf/F ormImpresionDictamen?OpenForm\&UNID=0BEA9AF6070E5E2A8425 7497006D174C 
Contraloría General de la República (2008): Dictamen No 2695, 22 de enero de 2008 [fecha de consulta: 24 de noviembre de 2009]. Disponible en: http:// www.contraloria.cl/LegisJuri/DictamenesGeneralesMunicipales.nsf/FormIm presionDictamen?OpenForm\&UNID=49D8E05ADCF1C1BE842571BD0 $\underline{04963 \mathrm{~F} 0}$

Contraloría General de la República (2006): Dictamen No 38949, 21 de agosto de 2006 [fecha de consulta: 24 de noviembre de 2009]. Disponible en: http://www.contraloria.cl/LegisJuri/DictamenesGeneralesMunicipales. nsf/FormImpresionDictamen?OpenForm\&UNID=A74256DE0B2D3F9F $\underline{\text { 842571D4005C509A }}$

Contraloría General de la República (2001): Dictamen No 49090, 28 de diciembre de 2001 [fecha de consulta: 24 de noviembre de 2009]. Disponible en: http://www.contraloria.cl/LegisJuri/DictamenesGeneralesMunicipales. nsf/FormImpresionDictamen?OpenForm\&UNID=272003FCD819BBEF $\underline{842571 B D 00519920}$

Contraloría General de la República (2001): Dictamen No 7828, 2 de marzo de 2001 [fecha de consulta: 24 de noviembre de 2009]. Disponible en: http:// www.contraloria.cl/LegisJuri/DictamenesGeneralesMunicipales.nsf/FormIm presionDictamen?OpenForm \&UNID=B559AB5659A41AA2842571BD00 $\underline{4 \mathrm{~A} 8 \mathrm{BF} 6}$

Contraloría General de la República (2001): Dictamen No 1075, 11 de enero de 2001 [fecha de consulta: 24 de noviembre de 2009]. Disponible en: http:// www.contraloria.cl/LegisJuri/DictamenesGeneralesMunicipales.nsf/FormIm presionDictamen? OpenForm \&UNID =03243760B97C584D842571BD00 $\underline{48 \mathrm{FB} 0 \mathrm{~A}}$

Contraloría General de la República (2000): Dictamen No 10555, 27 de marzo de 2000 [fecha de consulta: 24 de noviembre de 2009]. Disponible en: http://www.contraloria.cl/LegisJuri/DictamenesGeneralesMunicipales. nsf/FormImpresionDictamen?OpenForm\&UNID=12BFAC8672DBA563 $\underline{842571 \mathrm{BD} 004 \mathrm{~B} 309 \mathrm{~F}}$

Contraloría General de la República (1995): Dictamen No 40684, 18 de diciembre de 1995 [fecha de consulta: 24 de noviembre de 2009]. Disponible en: http://www.contraloria.cl/LegisJuri/DictamenesGeneralesMunicipales. nsf/FormImpresionDictamen?OpenForm\&UNID=DCFFA253730022E58 $\underline{42571 \mathrm{BD} 0050 \mathrm{C} 870}$

Contraloría General de la República (1993): Dictamen No 23443, 3 de septiembre de 1993 [fecha de consulta: 24 de noviembre de 2009]. Disponible en: http://www.contraloria.cl/LegisJuri/DictamenesGeneralesMunicipales. 
nsf/FormImpresionDictamen?OpenForm\&UNID=BAA1584884C30DCA 842571BD004DE6A1

Contraloría General de la República (1990): Dictamen No 31090, 9 de noviembre de 1990 [fecha de consulta: 24 de noviembre de 2009]. Disponible en: http://www.contraloria.cl/LegisJuri/DictamenesGeneralesMunicipales. nsf/FormImpresionDictamen?OpenForm \&UNID =27075B32B05E75C88 $\underline{42571 \mathrm{BD} 004 \mathrm{~F} 7459}$

Contraloría General de la República (1989): Dictamen No 34683, 29 de diciembre de 1989 [fecha de consulta: 24 de noviembre de 2009]. Disponible en: http://www.contraloria.cl/LegisJuri/DictamenesGeneralesMunicipales. nsf/FormImpresionDictamen?OpenForm\&UNID=5896A0DB20E376908 $\underline{42571 B D 00500200}$

Contraloría General de la República (1989): Dictamen No 32689, 6 de diciembre de 1989 [fecha de consulta: 24 de noviembre de 2009]. Disponible en: http://www.contraloria.cl/LegisJuri/DictamenesGeneralesMunicipales. nsf/FormImpresionDictamen?OpenForm\&UNID=2ED487B9189C532D 842571BD004FB4BD

Contraloría General de la República (1987): Dictamen No 21771, 7 de agosto de 1987 [fecha de consulta: 24 de noviembre de 2009]. Disponible en: http:// www.contraloria.cl/LegisJuri/DictamenesGeneralesMunicipales.nsf/FormIm presionDictamen?OpenForm\&UNID=D15684C602A11E11842571BD00 4D910C

Contraloría General de la República (1985): Dictamen No 15105, 1 de julio de 1985 [fecha de consulta: 24 de noviembre de 2009]. Disponible en: http://www. contraloria.cl/LegisJuri/DictamenesGeneralesMunicipales.nsf/FormImpresionD ictamen?OpenForm\&UNID=E4229FC08D1D068F842571BD004C2B00

\section{NORMAS JURÍDICAS CITADAS}

Ley No 19.995, establece las bases generales para la autorización, funcionamiento y fiscalización de Casinos de Juego. Diario Oficial, 7 de enero de 2005.

Decreto No 211 del Ministerio de Hacienda, aprueba reglamento para la tramitación y otorgamiento de permisos de operación de Casinos de Juego. Diario Oficial, 7 de enero de 2005.

Ley No 19.937, modifica el D.L. No 2.763, de 1979, con la finalidad de establecer una nueva concepción de la autoridad sanitaria, distintas modalidades de gestión y fortalecer la participación ciudadana. Diario Oficial, 24 de febrero de 2004 . 
Ley No 19.913, crea la Unidad de Análisis Financiero y modifica diversas disposiciones en materia de lavado y blanqueo de activos. Diario Oficial, 18 de diciembre de 2003.

Ley No 19.880, establece bases de los procedimientos administrativos que rigen los actos de los órganos de la Administración del Estado. Diario Oficial, 29 de mayo de 2003.

Ley No 19.623, sobre securitización y depósito de valores. Diario Oficial, 26 de agosto de 1999.

Decreto con Fuerza de Ley No 3, fija texto refundido, sistematizado y concordado de la Ley General de Bancos y de otros cuerpos legales que se indican. Diario Oficial, 19 de diciembre de 1997.

Ley No 19.301, modifica diversos cuerpos legales relativos a mercado de valores, administración de Fondos Mutuos, Fondos de Inversión, Fondos de Pensiones, Compañías de Seguros y otras materias que señala. Diario Oficial, 19 de marzo de 1994.

Ley No 19.132, crea Empresa Televisión Nacional de Chile. Diario Oficial, 8 de abril de 1992.

Ley No 18.933, crea la Superintendencia de Instituciones de Salud Previsional, dicta normas para el otorgamiento de prestaciones por Isapre y deroga el Decreto con Fuerza de Ley No 3, de salud, de 1981. Diario Oficial, 9 de marzo de 1989.

Ley No 18.876, establece el marco legal para la constitución y operación de entidades privadas de depósito y custodia de valores. Diario Oficial, 21 de diciembre de 1989.

Ley No 18.840, Ley Orgánica Constitucional del Banco Central de Chile. Diario Oficial, 10 de octubre de 1989.

Ley No 18.815, regula fondos de inversión; modifica Decretos con Fuerza de Ley Nos. 251 y 252, ambos del Ministerio de Hacienda, de 1931 y 1960, respectivamente, y la Ley No 18.045. Diario Oficial, 7 de julio de 1989.

Ley No 18.175, fija nuevo texto de la Ley de Quiebras. Diario Oficial, 28 de octubre de 1982.

Ley No 18.045, Ley de Mercado de Valores. Diario Oficial, 22 de octubre de 1981.

Ley No 18.046, Ley sobre Sociedades Anónimas. Diario Oficial, 22 de octubre de 1981.

Decreto Ley No 3.538, crea la Superintendencia de Valores y Seguros. Diario Oficial, 23 de diciembre de 1980. 
Decreto con Fuerza de Ley No 707, fija texto refundido, coordinado y sistematizado de la Ley sobre Cuentas Corrientes Bancarias y Cheques. Diario Oficial, 7 de octubre de 1980.

Decreto Ley No 2.079, fija texto de la Ley Orgánica del Banco del Estado de Chile. Diario Oficial, 18 de enero de 1978.

Decreto con Fuerza de Ley No 251, Compañías de Seguros, Sociedades Anónimas y Bolsas de Valores. Diario Oficial, 22 de mayo de 1931. 
